\title{
Motion Rail: A Virtual Reality Level Crossing Training Application
}

\author{
Luke Dando \\ CEMET, USW \\ Treforest, Wales, UK \\ luke.dando@southwales.ac.uk
}

\author{
Ikram Asghar \\ CEMET, USW \\ Treforest, Wales, UK \\ Ikram.asghar@southwales.ac.uk
}

\author{
Oche A Egaji \\ CEMET, USW \\ Treforest, Wales, UK \\ alexander.egaji@southwales.ac.uk
}

\author{
Mark Griffiths \\ CEMET, USW \\ Treforest, Wales, UK \\ mark.griffiths@southwales.ac.uk
}

\author{
Emma Gilchrist \\ Motion rail Ltd. \\ Ebbw Vale, Wales, UK \\ emma.gilchrist@motionrail.co.uk
}

\begin{abstract}
This paper presents the development and usability testing of a Virtual Reality (VR) based system named 'Motion Rail' for training children on railway crossing safety. The children are to use a VR head mounted device and a controller to navigate the VR environment to perform a level crossing task and they will receive instant feedback on pass or failure on a display in the VR environment. Five participants consisting of two male and three females were considered for the usability test. The outcomes of the test was promising, as the children were very engaging and will like to adopt this training approach in future safety training.
\end{abstract}

Virtual reality, safety training, railway crossing, education, interaction, real life scenario

\section{INTRODUCTION}

In the last few years, pedestrian safety on roads and railways have gained global importance from both academia and industry. Accidents on railway crossing around the world have caused many deaths and disabilities, especially in children. Generally, children are four times at risk when it comes to road and railway safety as compared to adults (Thomson, 2014).

The Department of Transport carried out a national travel survey (travel to school) which highlights the importance of this research. According to their findings, almost $46 \%$ of children aged between (5-10 years old) and $38 \%$ aged between (11-16 years old) walk to schools everyday (Transport, 2018). Hence, it is important that they understand and are able to use the roads and railway crossings safely.

There is an increasing need for campaigns that promotes educating children with cognitive skills like identification of safer railways crossings, judging distance from the crossing, manage their crossing timing and control their movements according to the environment (Foot et al., 2006).
In the last 10 years, Network Rail who control most of the UK railway tracks has done some notable work for safer railway crossings across the country by implementing some safety measures. In spite of all these efforts, Network Rail is still committed to innovation and using technology based solutions for safer railway crossings. Their long-term goal is to focus on technology-assisted solutions for the safety of railway level crossing users (NetworkRail, 2018a).

As a potential technological solution, this study proposes a novel Virtual Reality (VR) based system for training children on using railway crossing safely. There have been previous work on VR applications for traffic control on roads as discussed in the literature section. However, there is a lack of focus in using VR for railway safety training of children. VR provides an interactive approach to learning; it has the potential of increasing the user engagement, which in turns improves their knowledge retention over time. Research around this area indicates that increasing student interaction during learning can increase their achievement and knowledge retention (Fredricks, Blumenfeld, \& Paris, 2004).

The rest of the paper is organised as follows: Section 2 summarises literature relevant to this 
study. Section 3 explains the current prototype. Section 4 summarises the initial trials and the findings and Section 5 highlights conclusions and future work.

\section{LITERATURE REVIEW}

In the last decade or so, there have been a significant amount of research carried out in the field of VR assisted trainings in multiple research domains.

VR has been applied in three dimensions in social science. Firstly, VR has been used to test the differences in user experiences between the virtual world and real world, especially while evoking emotions. Secondly, VR has been applied to create training environments outside laboratory settings such as training surgeons in medical procedures. Thirdly, VR has been used in creating virtual environments to conduct controlled experiments that are rather cost effective solutions as compared to real world experiment environments (Fox, Arena, \& Bailenson, 2009).

In medical domains, VR has been used in experimenting with eating disorder patients through creating a virtual kitchen environment filled with fattening foodstuff and observed their emotional reactions to these foods (Gutiérrez-Maldonado, Ferrer-García, Caqueo-Urízar, \& Letosa-Porta, 2006). In another recent research, VR Exposure Therapy (VRET) was used to treat social anxiety to benefit people who stutter (Walkom, 2016).

VR has also been used for physical rehabilitation of patients through creating a risk free virtual environment and motivating patients to do different activities safely (J. Bailenson \& Yee, 2008). Interestingly, VR applications have been used for assisting stroke patients in regaining sense of balanced walking through a virtual environment, which helped them to regain their confidence (Deutsch \& Mirelman, 2007). In addition to this, a VR model of the human body was used to train medical students and doctors about human anatomy and complicated surgical methods in an interactive manner (Spitzer \& Ackerman, 2008).

Over the years, VR application in military operations have increased exceptionally due to decreased amount of risks and reduced costs for VR applications. Flight simulators are used for training flying skills rather than putting the new pilots straight into fighter jets. The virtual battle fields are used to train soldiers in making swift and active decisions during battle circumstances, etc. (Hill Jr et al., 2003).

VR application has expanded to schools as $\mathrm{J}$. Bailenson et al. created a virtual classroom in VR that enhances the teacher's and student's eye gaze. This enhancement resulted in greater learning ( $\mathrm{J}$. Bailenson et al., 2008).
VR is useful for controlled research experiments as well, as it creates the same environment for all the participants repeatedly which is difficult to maintain in real life scenarios (Blascovich et al., 2002). The VR environments are also useful for automated data collection while the participants are using VR applications. This helps to reduce difficulties faced in real life data collection through auto log maintenance (Bainbridge, 2007).

Some recent studies have already tried to use VR applications for traffic control. Researchers from the University of Strathclyde developed 'Crossroads', a VR resource for developing advanced level of traffic safety skills among 8 to 12 years old children. The 'Crossroads' is focused on using designated crossings, visual search and timing skills and learning to judge drivers' intentions (Thomson, 2014). Another study used simulations to educate children in understanding drivers signals to pedestrians like slow down, wait, carry on, etc. at the traffic crossing on roads (Foot et al., 2006).

The interactive nature and captivating power of VR enhances the feeling of being part of a virtual environment and doing actions closer to a real world environment. Additionally, VR implementations can be fruitful in training situations that involve dangerous and risky tasks to do in real life scenarios (Vafadar, 2013).

The paper's motivation to investigate the use of VR in railway safety training for children arises from: (i) the successful implementation of VR applications in multi-domains, and (ii) the ability of VR applications to engage the users more naturally.

\section{MOTION RAIL PROTOTYPE}

There are currently no railway safety training that takes the children beyond the classroom to evaluate how well they can utilise their taught skillsets in the real world (NetworkRail, 2018b). Hence, the use of VR for training children on safety measures on level crossing will present a cost-effective, risk free and a more effective approach than the alternative, which is taking the kids out of schools to an actual crossing. VR is appropriate for on-demand reproduction of reality, which is useful in tailoring the training to individual kid's needs, especially those with learning difficulties.

\subsection{Level Crossing Virtual Scenario}

There are several type of level crossing in the UK railway system; however, the most common ones are full barrier and half barrier crossings (NetworkRail, 2018a). This paper developed a half barrier crossing. The VR environment is composed of elements with similar characteristics as the physical world. It includes the external landscape such as the sky, grass, railway tracks, trains, power 
stations, roads and pavements. The VR environment incorporates sounds and ambient noise to bolster the user's immersion.

At the start of the level crossing scenario, the child should approach the level crossing on the side of a road causing the crossing to trigger. The sirens will sound and the barriers are lowered. The child can move (walk or run) in the VR space with the aid of a hand held controller. Any movement past the lowered barrier from the child is classed as an unsafe attempt to cross. Hence, when the child moves onto the track, they are first limited to a walking speed to give the train enough time to reach them. This functionality is important, as sometimes the children have no practical understanding of speed level, so they might try to outrun the train especially after waiting for a few minutes. The child is only allowed to move forward in the VR space with no backward movement. A snapshot of the VR environment is shown in Figure 1.

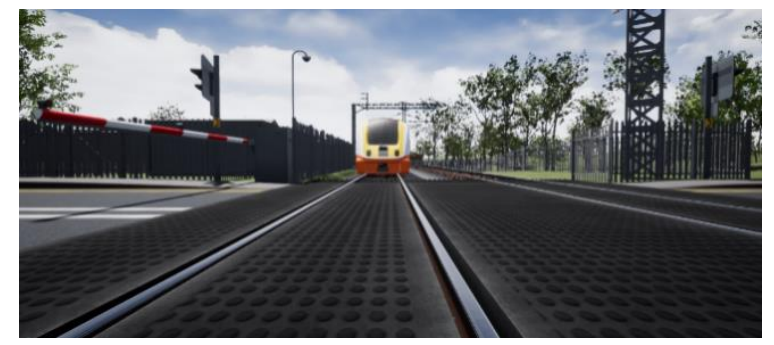

Figure 1: Training in Virtual Environment

Upon success or failure of the scenario, the children will find themselves on the other side of the track with a LED board that displays an appropriate message based on their performance. Another screen mirrors the children view in the VR environment to enable the teacher/observer to monitor their performance and provide the necessary feedback.

\section{TRIALS AND PROTOTYPE EVALUATION}

This section summarises the preliminary user experience testing on factors such as user friendliness, functionalities and efficacy of the prototype on children and young adults in Wales.

\subsection{Interface and Usability Evaluation}

This prototype has the potential of being used to train people of all ages, adults included. Bearing this in mind, five participants spanning various age groups as shown in Table 1 were considered for the initial test phase. The test participants consisted of two males and three females.

Table 1: Participant Profile

\begin{tabular}{|l|l|}
\hline User & Age Group \\
\hline 1 & $7-10$ \\
\hline 2 & $7-10$ \\
\hline
\end{tabular}

\begin{tabular}{|l|l|}
\hline 3 & $13-16$ \\
\hline 4 & $13-16$ \\
\hline 5 & $20-23$ \\
\hline
\end{tabular}

At the start of the testing, they were given a short presentation on how to use VR equipment, navigate the virtual scene and using the level crossing safely. There was an adult observer monitoring the performance of the participants through the display screen that mirrors the children field of view. The mounted VR headset on the participant is shown in Figure 2. In cases where the children fail to cross safely, they are allowed to run through the scenario again until they cross safely.

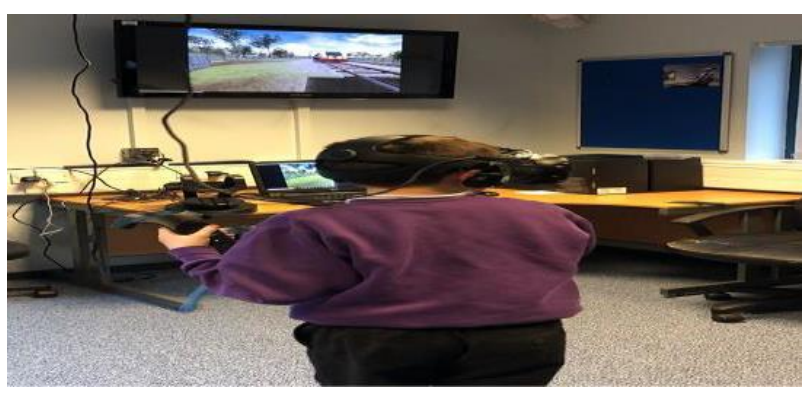

Figure 2: Participant with a mounted VR headset

\subsection{Questionnaires}

The participants had to answer some questions at the end of the test. The questionnaire as shown in Table 2 contained short and simplified questions, so the participants can easily understand these.

Table 2: Questionnaire

\begin{tabular}{|l|l|}
\hline No: & \multicolumn{1}{|c|}{ Questions } \\
\hline 1 & Did the VR Environment look real? \\
\hline 2 & How did the road looked? \\
\hline 3 & How did the pavement looked? \\
\hline 4 & Can you walk easily using hand held controller? \\
\hline 5 & Can you jog easily using hand held controller? \\
\hline 6 & Visual Impressions \\
\hline 7 & Audio sounds \\
\hline 8 & Gate closing \\
\hline 9 & Can you walk past the gate when it is closed? \\
\hline 10 & Did you see the train passing? \\
\hline 11 & $\begin{array}{l}\text { What happened, when user try to cross before } \\
\text { opening of the barrier? }\end{array}$ \\
\hline 12 & Did the barrier open? \\
\hline 13 & $\begin{array}{l}\text { What did you see when you crossed the } \\
\text { opened barrier? }\end{array}$ \\
\hline 14 & Learning Experience \\
\hline 15 & Retention \\
\hline
\end{tabular}

\subsection{Participants Response and Analysis}

All the test participants in the various age groups were happy with the VR environment (train, road and pavement) except for the concerns raised by 
one of the participant aged (7-10 years old) about the look of the train. This participant, will like the quality of the train to be improved so it looks more realistic. All the other participants were happy with the train and thought it looked real.

All the participants said the road and pavements looks good. And also, they found it easy to use the controller to walk and run in the VR environment except for one participant in the age group (13-16 years old) who physically tried to walk before realising there was no need of doing that. This was because it was the participant's first experience with the VR kits. The same participant also pointed out that walking or jogging in the VR environment via the controller is slow and the participant struggled going back.

The participants were questioned about their visual impression of the HMD display monitor. They were all happy with the visual quality of the display monitor except for one participant in the age group (13-16 years old) whose vision was initially blurring but became better after some time. This is sometimes common for first time users of the headset as their eyes takes time to adjust.

The participants were asked what happened when crossing whilst the barrier was down. This question was only applicable to one of the participant between the age group (7-10 years old) who tried crossing whilst the barrier was down, the participant reported a crash (been hit by a train). All other participants waited for the barrier to open before they attempted to cross the level crossing; hence, this question was not applicable to them.

All participants with the exception of one in the age group (7-10 years old) successfully crossed the railway on first attempt and saw a displayed 'Well done, you've crossed successfully' message at the other side of the crossing. The one participant that failed to cross on first attempt saw a message about been unsuccessful and to try again. The participant received feedback from the observer and safely crossed on the second attempt and saw the displayed message of crossing successfully. This message was a motivator for the participant to do better.

The participants were also asked about their learning experience and the most interesting comment came from one of the participant aged (710 years old) who failed on first attempt, the participant's response 'should not cross until the barrier opens'. This comment shows the worth of such trainings and strongly acknowledges the importance of a realistic experience after classroom training.

The immersive nature of the VR environment created the perception of being present in an actual railway crossing and enabled the children to interact with the environment in a seemingly real/physical way. According to the media equation by (Reeves \& Nass, 1996) people's response to mediated representation are fundamentally social and natural. Hence, this knowledge will be applied similarly in a realistic environment.

Overall, the participants showed great interest in learning through a VR environment. The participants were happy to use VR equipment. They enjoyed the experience, were satisfied with the training process, and will like this training approach to be adopted in future safety training.

\section{CONCLUSION AND FUTURE WORK}

This paper focuses on the development and testing of a VR based system for training children to understand safety issues in a railway level crossing. The initial testing and trial results revealed that children liked the VR based training system and showed considerable interest in learning. Interestingly, the results further highlighted that the children were able to grab and retain information from the VR environment.

Future work includes considering wider range of level crossing scenarios, involve wider age groups, increasing the test participants so the results can be generalised and involving a controlled group. The future work will hope to answer the research hypothesis centred on the user experience and usability of the VR training system. These hypotheses are:

$\mathrm{H} 1$ : The use of VR has positive impact of training children than current approach.

$\mathrm{H} 2$ : The children feel more connected to VR environment as compared to traditional classroom trainings.

H3: With VR environment, the children grabbed and absorbed more information.

H4: The children want to retain VR method for future trainings.

The psychological research on the benefit of using VR within education and training and its effects on children safety (through answering abovementioned hypothesis) would be great contribution to the body of knowledge.

Acknowledgements: The authors like to acknowledge the European Regional Development Fund (ERDF) and Welsh Government for funding this project. We will also like to acknowledge the role of Motion Rail and the CEMET teams throughout the project. 


\section{REFERENCE}

Bailenson, J., Patel, K., Nielsen, A., Bajscy, R., Jung, S.-H., \& Kurillo, G. (2008)a. The effect of interactivity on learning physical actions in virtual reality. Media Psychology, 11(3), 354-376.

Bailenson, J., \& Yee, N. (2008)b. Virtual interpersonal touch: Haptic interaction and copresence in collaborative virtual environments. Multimedia Tools and Applications, 37(1), 5-14.

Bainbridge, W. S. (2007). The scientific research potential of virtual worlds. science, 317(5837), 472-476.

Blascovich, J., Loomis, J., Beall, A. C., Swinth, K. R., Hoyt, C. L., \& Bailenson, J. N. (2002). Immersive virtual environment technology as a methodological tool for social psychology. Psychological Inquiry, 13(2), 103-124.

Deutsch, J., \& Mirelman, A. (2007). Virtual realitybased approaches to enable walking for people poststroke. Topics in Stroke Rehabilitation, 14(6), 45-53.

Foot, H. C., Thomson, J. A., Tolmie, A. K., Whelan, K. M., Morrison, S., \& Sarvary, P. (2006). Children's understanding of drivers' intentions. British Journal of Developmental Psychology, 24(4), 681-700.

Fox, J., Arena, D., \& Bailenson, J. N. (2009). Virtual reality: A survival guide for the social scientist. Journal of Media Psychology: Theories, Methods, and Applications, 21(3), 95.

Fredricks, J. A., Blumenfeld, P. C., \& Paris, A. H. (2004). School engagement: Potential of the concept, state of the evidence. Review of educational research, 74(1), 59-109.

Gutiérrez-Maldonado, J., Ferrer-García, M., Caqueo-Urízar, A., \& Letosa-Porta, A. (2006). Assessment of emotional reactivity produced by exposure to virtual environments in patients with eating disorders. CyberPsychology \& Behavior, 9(5), 507-513.
Hill Jr, R. W., Gratch, J., Marsella, S., Rickel, J., Swartout, W. R., \& Traum, D. R. (2003). Virtual Humans in the Mission Rehearsal Exercise System. Ki, 17(4), 5-.

NetworkRail. (2018a). Level Crossings. Retrieved from https://www.networkrail.co.uk/running-therailway/looking-after-the-railway/level-crossings/

NetworkRail. (2018b). Safety Education. Retrieved from https://www.networkrail.co.uk/communities/safet $y$-in-the-community/safety-education/

Reeves, B., \& Nass, C. I. (1996). The media equation: How people treat computers, television, and new media like real people and places: Cambridge university press.

Spitzer, V. M., \& Ackerman, M. J. (2008). The Visible Human $\AA$ at the University of Colorado 15 years later. Virtual Reality, 12(4), 191-200.

Thomson, P. J. (2014). Adoption of behavioural roadside training programme improves children's road crossing skills. Retrieved from http://impact.ref.ac.uk/CaseStudies/CaseStudy.a spx? $\mathrm{ld}=42294$

Transport, D. O. (2018). National Travel Survey 2014: Travel to School. Retrieved from https://assets.publishing.service.gov.uk/governm ent/uploads/system/uploads/attachment_data/file /476635/travel-to-school.pdf.

Vafadar, M. (2013). Virtual Reality: Opportunities and Challenges. International Journal of Modern Engineering Research (IJMER), 3(2), 11391145.

Walkom, G. (2016). Virtual Reality Exposure Therapy: To Benefit Those Who Stutter and Treat Social Anxiety. Paper presented at the Interactive Technologies and Games (iTAG), 2016 International Conference on. 